what one has learned seem to be the same thing. HM showed that these are in fact two separate types of memory.

Further work with HM also forced Corkin to reconsider the initial idea that his operation had effectively cut his memory into two neatly separated temporal compartments. This was true for his vocabulary: his world remained one of rocketeers, never of astronauts. But when Corkin asked HM in 1966 to draw the floor plan of the house he had moved into five years after his operation, he produced an accurate plan from memory. When he moved house, however, HM would get lost and show up at the doorstep of his former home.

Several details on HM's personal life were already available in 1995, when science writer Philip J. Hilts published his compelling book Memory's Ghost (Touchstone, 1996). Where Hilts and Corkin seem to diverge is in their appreciation of Scoville's operation. Corkin does sketch Scoville's questionable background in lobotomy, but is somewhat apologetic on the bilateral resection. Hilts is considerably more critical, mentioning that Montreal neurosurgeon Wilder Penfield "exploded into the telephone" when Scoville called him with the details of HM's surgery. Ironically, the Scoville and Milner 1957 paper, 'Loss of Recent Memory after Bilateral Hippocampal Lesions', became a citation classic and the operation on HM developed into Scoville's claim to fame.

In 2002, Corkin announced that HM had agreed to donate his brain to science. She decided that Jacopo Annese, head of the Brain Observatory at the University of California, San Diego, was the person for the job. HM's brain even raised funding after his death: for US\$50, visitors to the Brain Observatory site could sponsor one of the 2,401 slide-mounted sections into which it had been sliced.

The exact locations of the lesions that caused HM's amnesia were ascertained by high-resolution magnetic resonance imaging scans, made a few hours after his death. HM's virtual brain will probably take its place among relics of neurology such as the skull and iron rod of Phineas Gage and the brain of the speechless Monsieur Tan, neurologist Paul Broca's patient. Whether it will serve as an opportunity for future research remains to be seen, but HM will live on in other ways. The rights to make a film about his life have been sold to Columbia Pictures and Scott Rudin, who in 2007 produced No Country for Old Men.

Douwe Draaisma is professor of the history of psychology at the University of Groningen, the Netherlands. His book The Nostalgia Factory will be published in September 2013. e-mail:d.draaisma@rug.nl

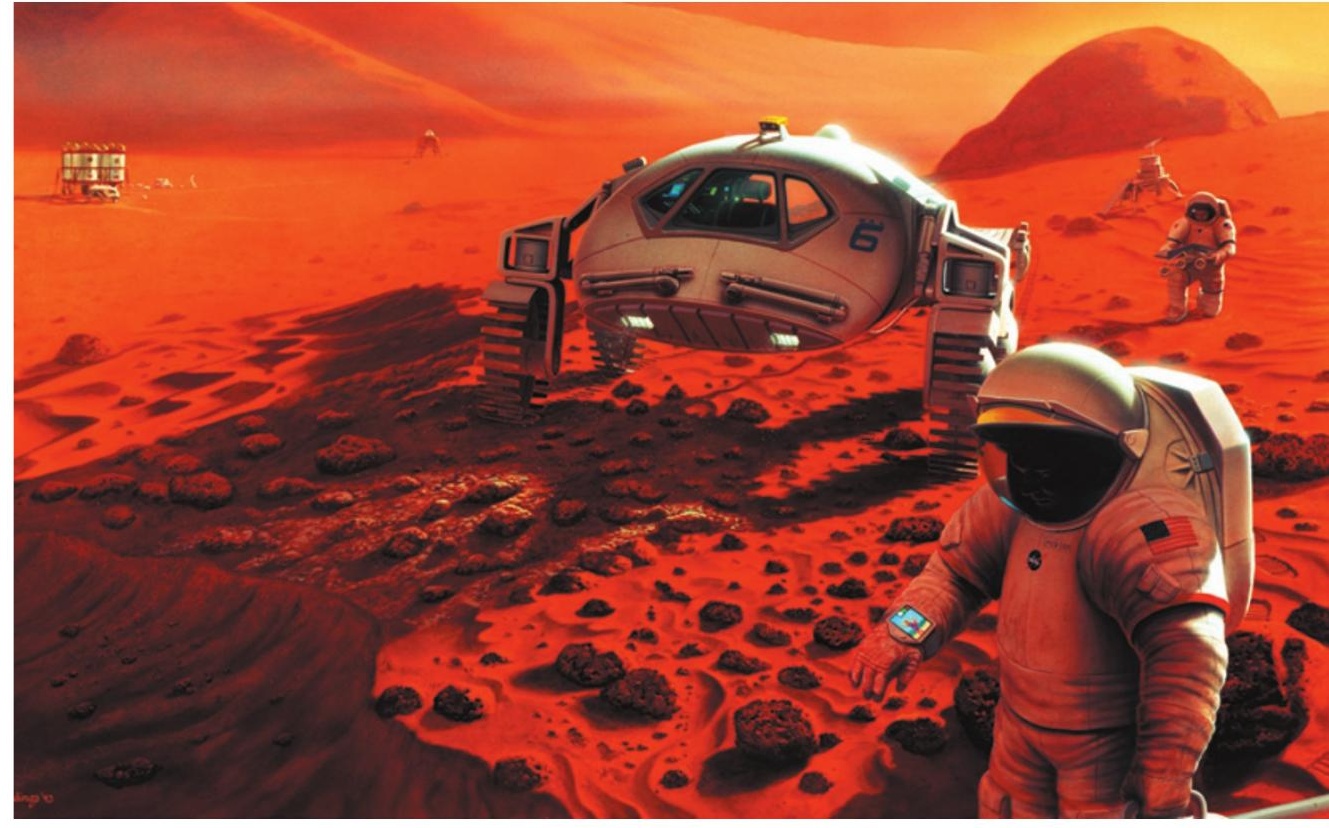

An artist's impression of a future mission to the red planet.

SPACE EXPLORATION

\title{
Life on Mars
}

\section{Jim Bell welcomes a detailed blueprint for colonizing the red planet from Apollo 11 veteran Buzz Aldrin.}

$\mathrm{F}$ Tor many, our exploration of the cosmos seems to hinge on grand and singular theoretical observations and technological achievements such as those of Galileo and Einstein. We are fascinated by paradigm-shifting discoveries and personal stories - the oppressed astronomer, the quirky professor. Yet in the arena of global science and engineering, it often takes the less flashy, more mundane development of good policy and follow-on infrastructure to maintain and sustain those changes, and to enable even more discoveries.

In Mission to Mars, celestial-mechanics expert and Apollo 11 astronaut Edwin ('Buzz') Aldrin, with space journalist Leonard David, argues that achieving the next great singular goal in space exploration - a sustained campaign to explore and ultimately settle Mars - will require a healthy dose of such pragmatism. The United States will, they say, need both significant advances in its space transport infrastructure and considerable changes in space policy.

Ever since his historic 1969 lunar-landing mission, Aldrin has been a passionate and outspoken advocate for continued US leadership in space exploration. Calling the space shuttle programme "bad judgment" because it placed humans and cargo together, and a second race to the Moon "a

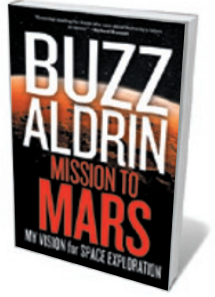

Mission to Mars: My Vision for Space Exploration BUZZ ALDRIN

National Geographic Society: 2013. 272 pp. $\$ 26(£ 17.99)$

development. He goes
on to write that "America's space program should help other nations achieve what we have already done", and echoes the controversial call to bring both China and India in as International Space Station partners.

These and other recommendations from one of America's first moonwalkers make Mission to Mars more than just a plea for exploration of the red planet. Aldrin outlines what he calls his "Unified Space Vision", which he believes is needed to enable humanity to establish permanent settlements beyond Earth. Some of its crucial elements would be an independent think tank to advise government, industry and the public on space issues, 
an international lunar-development authority to oversee the eventual economic exploitation of the Moon, and a planetary-defence component to advance our understanding of the science and mitigation strategies for potentially hazardous near-Earth asteroids.

Perhaps Aldrin's most passionate call, however, is for the development of a fully reusable interplanetary transport infrastructure between Earth and Mars. This would break through the current 'reusability barricade' for space travel, an achievement that was visualized for the space shuttle, but never fully realized. A key advance would be to implement Aldrin's long-standing idea of 'cycler' spacecraft: ferries set in motion on permanent looping trajectories around the gravitational orbits of Earth and Mars (or other staging destinations, such as the Martian moons). There are many technical issues that limit such a concept: for example, passengers to and from these destinations would have to use some sort of shuttlecraft to catch up with the nonstop, high-velocity cyclers. But Aldrin rightly points out that without the infrastructure in place for transportation, as well as for essential long-term resources such as fuel, food and water, we will continue to make only small steps, rather than the next giant leaps, in our exploration of the worlds around us.

I was perhaps most struck by Aldrin's rejection of the idea of returning to the Moon before any foray to Mars. "Don't put any more NASA astronauts on the Moon!" he implores. Indeed, his philosophy is consistent with the current space policy of President Barack Obama's administration, which includes NASA's recently announced idea to attempt to capture a small near-Earth asteroid. This mission is poorly defined at present, but if eventually implemented it could be consistent with Aldrin's call for testing new deepspace rocket components, and for potential scientific and planetary-defence research on near-Earth asteroids. Some of Aldrin's ideas may be having an impact at the highest levels.

We idolize aviation pioneers and their many 'firsts', but take for granted today's global air-transport infrastructure predicated on their achievements. Even the Global Positioning System can be traced back directly to the ventures of NASA and other space agencies. Buzz Aldrin doesn't want us to forget earlier heroic achievements. But he desperately wants us to get to work on the infrastructure and policies needed to make humanity a multi-planet species with an interplanetary economy.

Jim Bell is a planetary scientist and professor in the School of Earth and Space Exploration at Arizona State University in Tempe. He is president of the Planetary Society, the world's largest public space-advocacy organization. His latest book is The Space Book. e-mail:jim.bell@asu.edu

\section{Books in brief}

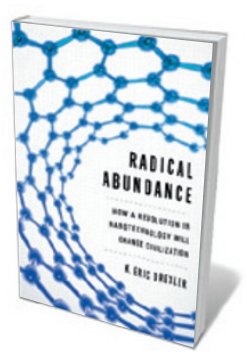

Radical Abundance: How a Revolution in Nanotechnology Will Change Civilization

K. Eric Drexler PUBlicAfFAIRS 368 pp. \$28.99 (2013)

Nanotechnology pioneer Eric Drexler bids us to leap in at the technological deep end. We can transform the way we make everything from bridges to circuit boards, he argues, by harnessing molecular machines that operate on digital principles. The result? Desktop or garage facilities that use less fuel, land and energy than today's vast factories and supply chains. The technical and political challenges of unleashing 'atomically precise manufacturing' are substantial, but Drexler cuts deftly through the complexities.

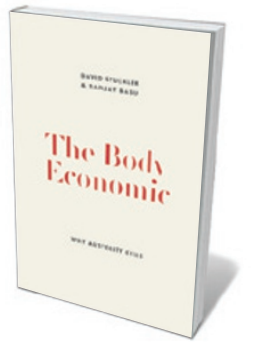

The Body Economic: Why Austerity Kills

David Stuckler and Sanjay Basu BASIC Books 240 pp. \$26.99 (2013)

What price a healthy stock market? In this stringent economic analysis, sociologist David Stuckler and epidemiologist Sanjay Basu argue that during a recession, austerity-based cuts to social spending erode public health. Their findings reveal that in cutriddled Greece, suicide rates soared by $20 \%$ between 2007 and 2009, and new HIV cases rose by $52 \%$ in the first half of 2011. Meanwhile Iceland, despite its sharp recession, has maintained social safety nets and the health of its population. A sobering call for democratic, informed choices in response to recession.

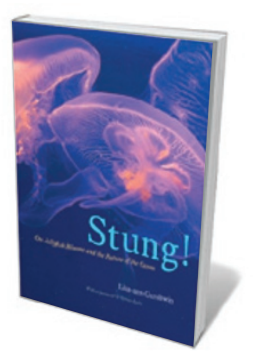

Stung! On Jellyfish Blooms and the Future of the Ocean Lisa-ann Gershwin UNIVERSITY OF CHICAGO PRESS 456 pp. \$27.50 (2013)

In this bleak take on the future of our seas, Lisa-ann Gershwin chronicles in sometimes exhausting detail how the gelatinous omnivores that are jellyfish are wreaking havoc in waters around the globe. As reams of evidence reveal, human changes to ocean ecosystems are producing perfect conditions for jelly-dominated seas. The switches from chatty to technical language and copious references can jar; but this is a comprehensive summary of the irresistible rise of an arguably unstoppable creature.

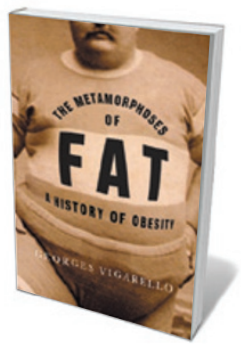

The Metamorphoses of Fat: A History of Obesity

Georges Vigarello (translated by C. Jon Delogu) COLUMBIA UNIVERSITY PRESS 296 pp. \$29.50 (2013)

Corpulence and humanity's shifting perceptions of it feature in this curious 'history of the body'. In Jon Delogu's translation, sociologist Georges Vigarello takes us from the twelfth century, when 'fat reduction' was attempted by cutting the limbs with razors to allow the escape of 'wind', to today's confused and often destructive dynamics of thinness and obesity. Vigarello offers up a grande bouffe of food for thought, tracing the impact of evolving mores and medicines on society's perception of an often stigmatized condition.

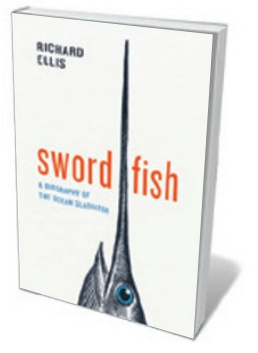

Swordfish: A Biography of the Ocean Gladiator

Richard Ellis UNIVERSITY OF CHICAGO PRESS 272 pp. £18 (2013)

Blue-eyed, bulky, fast and sporting a sword-like upper jaw, the broadbill swordfish (Xiphias gladius) emerges in marine natural historian Richard Ellis's portrait as an 'apex' predator with real charisma. At home anywhere from the ocean surface to 600 metres down, its unusual adaptability stems partly from specialized thermogenic tissue in its head that keeps its brain warm and protects its central nervous system. A fascinating dip into the history and biology of a seagoing sabre fighter. Barbara Kiser 